\title{
Research on the Golden Seal of Zhang Dageng of Ming Dynasty Unearthed in Fuyang, Anhui and Related Imprints
}

\author{
Qi Zhu ${ }^{1, *}$ \\ ${ }^{1}$ Nanjing Xiaozhuang University, Nanjing, Jiangsu 210017, China \\ *Corresponding author. Email: zhuqi1980@163.com

\begin{abstract}
A tortoise gold seal was unearthed in Fuyang, Anhui in the 1980s, which enjoys high value of cultural relics. This paper makes emendation of the annotations in the original brief, and conducts a comprehensive study on the material, shape, characteristics, production method and artistic style of the gold seal. Comparative study of the imprints on the fan of painting collection of Zhang Dageng contributes to clarify the relationship between Zhang Dageng, the collector, and Cheng Yuan, the engraver of Ming Dynasty. The phenomenon of imprints and "seals with same pattern" in identification of ancient paintings and calligraphy are analyzed to make clear the reasons behind.
\end{abstract}

Keywords: Zhang Dageng, gold seal, seal cutting, art archeology

\section{INTRODUCTION}

During the Chinese Memorial Day in 1984, an ancient tomb was found on the south slope of Luohan Qigu mound in Yingxi Town, Fuyang City, Anhui Province. A gold seal was discovered when the cultural relics department of Fuyang city cleaned it up. The seal is made of pure gold, with a turtle knob and characters cut in intaglio ("Fig. 1"), measuring $16 \times 16 \times 21 \mathrm{~mm}$ and weighing 32 grams. The brief claimed that the text was "Zhang Dageng Yin (张大庚印)". Geng (庚) is 蔓 when written in small seal (a style of calligraphy), while the exact one is 首. Therefore, the interpretation should be corrected to "Zhang Dageng Yin (张大费印)" ("Fig. 2"). The tomb is a pit tomb, and the unearthed objects include two bronze mirrors and coins in the early Qing Dynasty in addition to gold seals. The unearthed seal showed that it was the couple's joint burials. The seal is now listed as a national first-class cultural relic and collected in Fuyang Museum.

*Fund: This paper is one of the phased research results of the general project "Research on the Context of Jiangsu Modern and Contemporary Ink Painting" (Project Approval No.: 19YSB009), a general project of the Jiangsu Provincial Social Science Foundation.

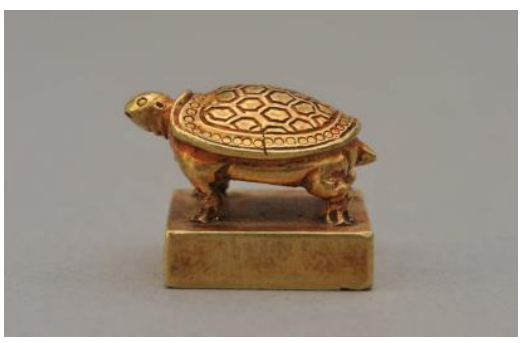

Fig. 1. The seal.

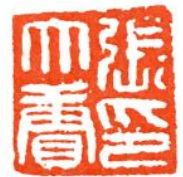

Fig. 2. Zhang Dageng (费) Yin

II. THE GOLDEN SEAL OF ZHANG DAGENG UNEARTHED IN FUYANG AND ITS ARTISTIC FEATURES

The preciousness of this seal lies on its material. Gold, the elemental form of the chemical element gold $(\mathrm{Au})$, is a relatively rare traditional precious metal. Gold output in ancient times was extremely low, with studies suggesting that worldwide gold output was less than 10,000 tons for thousands of years prior to the 19th century. For example, historical records and archaeological excavations show that China's gold reserves in the Western Han Dynasty were relatively 
high, with official reserves totaling more than 200 tons. Gold seals were an important product in the history of ancient Chinese gold craftsmanship. However, its quantity is no match for that of copper seals in terms of existing number.

According to Han Dynasty's Old Ceremonial Customs (《汉旧仪》) by Wei Hong, "Before the Qin Dynasty, people used to wear ribbons and keep their seals in different styles. The seals were made of gold, silver, copper, rhinoceros horn and ivory", which proves the existence of gold seals before the Qin Dynasty. However, no actual gold seals in the Warring States Period were found. Wang Rencong once mentioned in a paper that a gold seal of Qin during the Warring States Period is engraved with "Chang She Jun $\mathrm{Xi}$ (长邤君坌)", which is believed to be the earliest gold seal ever seen. But the authenticity of the gold seal is still controversial. ' Han Dynasty's Old Ceremonial Customs (《汉旧仪》) also writes that gold seal used by crown prince with turtle knob is called zhang (章), the seals of feudatory kings fastened with camel knobs were called royal seal (坌) and decorated with red ribbons. The gold seal with turtle knob used by Liehou (adjunct marquises) is called yin (印). The gold seal with turtle knob used by the prime minister and the general is called zhang (章). The gold seal with camel knobs used by chief of the Xiongnu in ancient China was called zhang (章)." Existing historical materials reveal that only the following are entitled to use golden seals: crown prince, feudatory kings, liehou, Guannei marquis, nobleman, officials, prime minister, general, general of chariots and cavalry, guard generals, the front, behind, left and right generals, and the top leaders of the minority nationalities such as chief of the Xiongnu in ancient China. At present, the authentic gold seals unearthed early are mostly of the Western Han Dynasty, such as "Wan Qu Hou Zhi (宛朐侯执)" from Liuzhi Tomb in Xuzhou, "Zhu Guo Hou Yin (诸国 侯印)" from Jimo, Shandong, and "Shi Luo Hou Yin (石 洛侯印)" from Rizhao, Shandong in Qing Dynasty, etc.

During the Southern and Northern Dynasties, groups entitled with access to gold seals are expanding, but still limited to the upper nobility and senior officials. The actual situation of archaeological excavations shows that the existing gold seals are mainly official seals. The gold seals unearthed for personal use were rare. The unearthed private gold seals in the Western Han Dynasty include "Min Du Jun Yin (闵都君印)" unearthed in Fuxing Road, Changsha in 1976, "Ru Xin (如心)" unearthed in the Western Han Tomb of Gaozhai County, Guangxi province, and

\footnotetext{
According to the letter from Sun Weizu of Shanghai Museum, the authenticity of this seal should be questioned
}

"Wang Jing (王精)" tortoise gold seal ("Fig. 3") unearthed in the Western Han Tomb of Shapo, Xi'an in 1983.

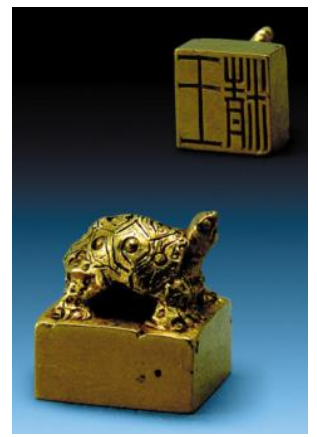

Fig. 3. "Wang Jing (王精)" tortoise gold seal.

The unearthed gold seals of Northern and Southern Dynasties were few in number, let alone the one employed by celebrities. Therefore, the "Zhang Dageng Yin" was very precious even though it was of a later age. The seal has been polished in detail. Although its form mimics that of the seal in Han Dynasty, the seal nose and shape are quite different from those of the Han Dynasty. The turtle's shape tends to be concrete and the ornamentation is more delicate. Seal nose is featured with protracting turtle head, back with a slight bulge, and short and protruding tail. There are hexagonal lines on the back of the turtle, a circle engraved with circular fish grain. In the Han Dynasty, the seal with turtle knob squatted down, stood up on four feet, and had obvious pleats on the legs. Its shape was similar to that of seal with turtle knob after the Jin Dynasty, especially the Northern Dynasty. ("Fig. 4")

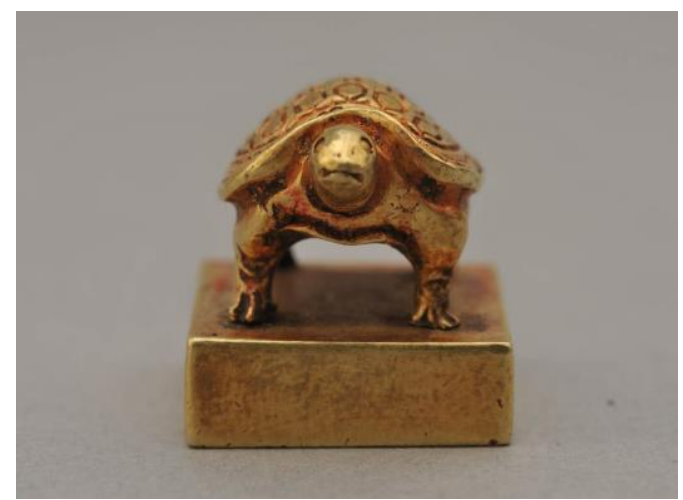

Fig. 4. The seal with turtle knob squatted down, stood up on four feet, and had obvious pleats on the legs.

The gold seal of the Han Dynasty was second only to the jade seal. Yin Dian (《印典》) by Zhu Xiangxian in the Qing Dynasty records: "The gold seal was used by the nobility of the Han Dynasty. Gold seals for private use also exist. The characters are beautiful. Although valuable, it is underappreciated, and the ancient gold 
seal is only a status symbol." The ancient people made the seal with gold, which reflected the noble status of the seal holder. However, due to the rare production of gold in ancient times, the official seal granted to the nobility of minority that should be of gold quality are of gold or copper in reality, which is common in Wei, Jin, and Five Dynasties. After the Tang, Song and Yuan Dynasties, the number of gold seals awarded was even lower.

\section{ZHANG DAGENG'S LIFE STORY}

Zhang Dageng (1600-1674), styled himself Sufu or Shishui, was born in Yingzhou (now Tianpengji, Chaiji District, Funan County, Fuyang City, Anhui), and was the third son of Zhang Heming (1551-1635), Minister of War in the late Ming Dynasty. In the eight years of Chongzhen (1635), Zhang Xianzhong captured Yingzhou. Zhang Heming organized local armed resistance, which is recorded in History of the Ming Dynasty (《明史》). Zhang Dageng is good at poetry and painting. After the collapse of the Ming Dynasty, he devoted himself to learning and never engaged in office. (Qianlong) Jiangnan Tongzhi (《(乾隆) 江南通 志》) covers a biography of Zhang Dageng:

Zhang Dageng, styled Sufu, is from Yingzhou. He was the son of Heming. He was privileged to be an official because of the achievements of his earlier generation. He was fond of reading, poetry, and painting. As his hometown Yingcheng fell, his father, brother and uncle all died on the same day, totaling more than 30 people. Dageng, with an intention to save his father, cursed the thief, but fainted on the ground. He didn't wake up until the thief left. After burying his family and dressing himself, he immediately went to the capital to petition the court together with his elder brother, Zhang Dazhuang. Zhang Heming was given a sacrificial offering, while Zhang Heteng and Zhang Datong were also praised.

(Daoguang) Fuyang County Annals (《( 道光) 阜阳县 志》) shares the same narration, while some details are added.

It was the Qing Dynasty that dedicated itself to attracting reclusive scholars. The person in charge intended to recommend Zhang Dageng, but was vigorously rejected. He lived comfortably in the village, and writing poems every day. In the spring of 1674, he died peacefully, sitting upright. $\mathrm{He}$ is the author of $\mathrm{Ba}$ $Y u$ Xuan Shi (《拔玉轩诗》), Shui Xin Ji (《睡心集》), Shi Lin Xiao Zhi (《诗林笑旨》), Xu Tong Shu (《续同书》), Du Shi (《妬史》), Shang Zheng Hua Lue (《解政画略》), Pai $\mathrm{Pu}$ (《牌谱》), Song Cha Za Ji (《松察杂记》), and so on.

Zhang Dageng Yin imitates the private seals of the Han Dynasty, with Miu Zhuan characters and plain and simple style. ${ }^{2}$ Shuo Wen Jie Zi (《说文解字叙》) by $\mathrm{Xu}$ Shen of Eastern Han Dynasty writes that there were eight fonts in the Qin Dynasty, and the fifth is Miaoyin (a style of characters or lettering on ancient imperial seals). After Wang Mang's Reform, the number of fonts is reduced to six, and the fifth is Miao Zhuan. In other ways, Miao Zhuan refers to Miaoyin (a style of characters or lettering on ancient imperial seals), a typeface used in the Han Dynasty to copy seals. The round and mellow small seal of Qin evolved into a square and well-balanced conformation with the strokes of clerical script (an ancient style of calligraphy current in the Han Dynasty). Zhang Dageng Yin is made through chisel, and it is common to see the chisel carving around the bend. The long horizontal line in "费 " and the curve of "弓" in "张" reveal that the maker chiseled along the stroke of the two contour lines. A stroke is carved twice along the contour line from both ends, which is also known as the "double-input technique". The impression indicates ("Fig. 5") that the tool used should be relatively sharp. After the two sides of the lines are cut, the internal cutting is carried out. This carving method is obviously influenced by the cutting methods of the Ming and Qing dynasties and is quite different from the traditional cutting tools used in the Qin and Han Dynasties.

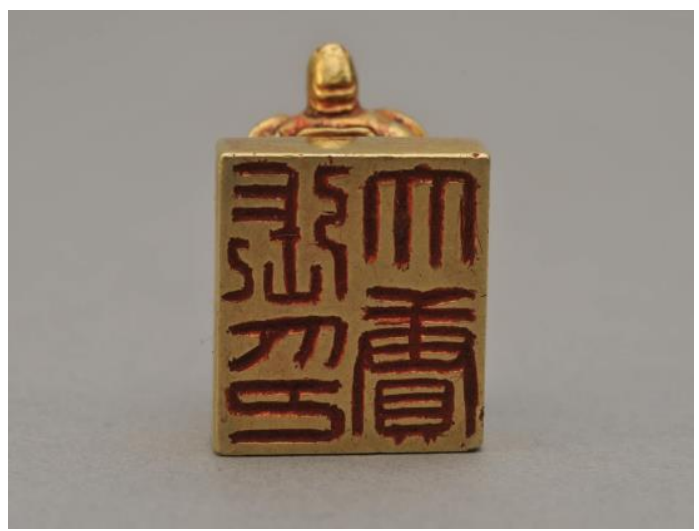

Fig. 5. A stroke is carved twice along the contour line from both ends.

Zhang Heming, Zhang Dageng's father, was a public official of the Ming Dynasty. He served as Minister of War, Minister of Industry, grand guardian of the heir apparent, and officer who tutors the crown prince. Born into a family of public officials, Zhang Dageng was able to use personal seal made of gold,

2 The "double-input technique (双入正刀法)" is characterized by "double-input into the stone on both sides, with no light slippery", which is proved in Xu Rong's Seal Character (《说管》 ), Selected Papers on Seal Studies (《历代印学论文选》) edited by Han Tianheng, Xiling Seal Engraver's Society Publishing House, Second Edition, 1999, p. 176. 
reflecting his personal status and economic status. It also shows that in the late Ming and early Qing Dynasties, the selection of seal materials was also influenced by the ancient imperial rules and regulations, which indirectly revealed the psychological expectation of "gold and stone last forever". Although the gold seal was unearthed from tomb, its delicacy and abrasion showed that it was not a makeshift carved for burial, but a treasure for practical use. His family consciously chose the precious private seal used by the tomb owner to be buried with him so that he could use it in the nether world. It was consistent with the family's identity and status, and also reflected the public funeral concept of "dead as alive".

\section{INVESTIGATION ON THE HISTORY OF SEAL INVOLVING ZHANG DAGENG}

According to his biography, Zhang Dageng was very skillful in painting. Similarly, the "Image of the Pipa" painted by Chen Ren (styled Shanchang) of Suzhou during the Ming Dynasty shows "Zhang Dageng Yin" ("Fig. 6") on the fan ("Fig. 7"). It is located in the lower left corner of the fan, indicating that it was drawn by the collector. The fan includes Pipaxing (《琵琶行》) written by Cheng Yuan in regular script in small characters ("Fig. 8"). And the inscription is as follows: "天启辛酉冬甲子后一日，鄣山人程远书". 天启 辛西 refers to the year of 1621, when Zhang Dageng was only 22 years old. Therefore, it was impossible for him to communicate directly with Cheng Yuan, which means that it may be paintings by previous generation collected by Zhang Dageng.

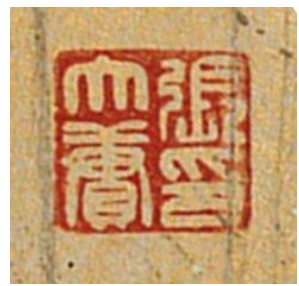

Fig. 6. "Zhang Dageng Yin".

Fig. 7. "Zhang Dageng Yin"on the fan.

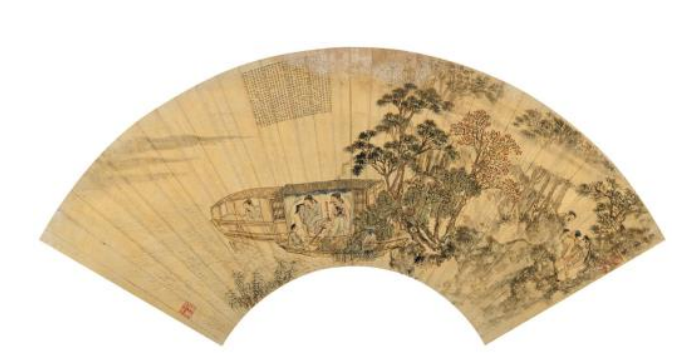

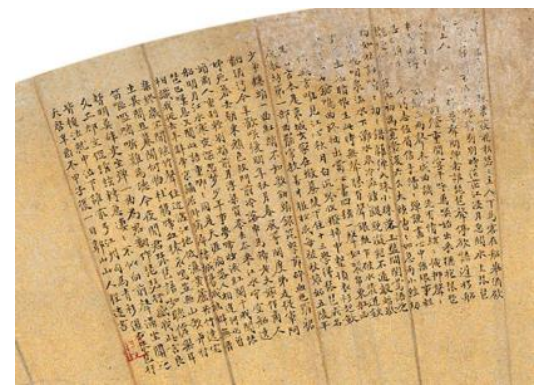

Fig. 8. Pipaxing written by Cheng Yuan in regular script in small characters.

Cheng Yuan, styled Yanming, was born in Liangxi (now Wuxi, Jiangsu). His birth and death years are not known. He was a seal engraver in the Ming Dynasty. He used to copy the ancient seals and seals of talents in Ming Dynasty in Wanwei Tang, Jiaxing. In the thirtieth year of Wanli (1602), he compiled these collections into four volumes ("Fig. 9") of Ancient and Modern Seals (《古今印则》), followed by one volume of Seal Engraving (《印旨》) on seal cutting. Dong Qichang praised him, saying, "My friend Cheng Yanming's calligraphy and seal cutting are both beautiful. People with good taste compare him to Wen Shoucheng and He Changqing. Scholar-official are crazy about his seals." This shows that he was good at calligraphy, and his engravings were praised by Dong Qichang and Chen Jiru to be in line with those of Wen Peng and $\mathrm{He}$ Zhen. The seals used by Dong Qichang and other famous scholars were mostly made by Cheng Yanming, but his seals and inks handed down are rare. The prefaces of Cheng Yuan's Ancient and Modern Seals ( 《古今印则》) were written by Zhu Zifan, Tu Long, Zhang Nabi, Gui Changshi, Gu Qiyuan, Shen Que, Wang Zhideng, Yao Shilin, Dong Qichang, Zhang Fengyi, Yu Chunxi, all of which are famous. The views in Seal Engraving (《印旨》) are incisive and of high artistic theoretical value. 


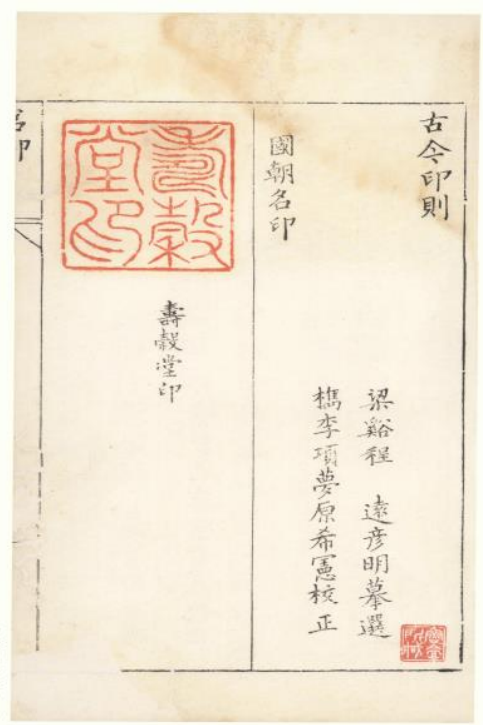

Fig. 9. Four volumes.

Cheng Yuan signs off by saying "Zhangshan Ren," which may be his nickname, but is not seen in other materials. Jixi, Anhui includes Zhangshan, also known as Da Zhangshan, named after Zhang County in the Qin Dynasty. (Qianlong) Jixi County Annals (《绩溪县志》 )writes: Among the mountains of Jixi, Da Zhangshan is the most honored, which is nicknamed father of the mountains. Its main peak is at the boundary of Shexian County and Lin'an City, Zhejiang Province. It is recorded in the literature that Cheng Yuan was a native of Liangxi. ${ }^{3}$ However, Cheng family is popular in She County, Huizhou in the Ming Dynasty. Famous people engaged in seal cutting during the Ming and Qing Dynasties, including Cheng Yuan, Cheng Pu, Cheng Qi, Cheng Sui, are native of She County. If the possibility that two people both named Cheng Yuan were good at calligraphy was ruled out, the nickname of "Zhangshan Ren" may be related to his ancestral home, which has not yet be confirmed in existing materials.

Interestingly, Zhang Dageng Yin on the fan is very similar to the unearthed gold seal, but they are not the same after careful observation. The duo are same in pattern, art of composition, and cutting, and nuances are found only in details. So it is very likely that the two seals were carved by the same person. But the seal on the fan is more neat than the one unearthed, and it's not made of metal but of stone. Therefore, the former one is more mature, and easier to express the seal character and implication.

According to the title of the first volume of Ancient and Modern Seals and the prefaces and postscripts of Gui Changshi, Chen Jiru and others, they all styled themselves as "Liangxi" people, which can be seen in printed version in the 30th year of Wanli in Ming Dynasty.

\section{CONCLUSION}

The Chinese literati seal cutting originated in the Tang and Song Dynasties, while the seal cutting art in the Ming Dynasty. Generally, the physical evidence of such art is the author's consciousness, which is reflected in Zhi Yin Shu Kuan (治印署款) as for seals. ${ }^{4}$ However, the research on the early seal cutting history is crippled by the antiqueness and lack of actual seals without definite signature. The only helper is "imprints" covered on the literature that is handed down for generations, which is literature themselves. Therefore, research on imprints handed down for generations is actually different from that on history of seal cutting (that is, the "history of seal cutting of a particular school") centered on the seal engraver, which can be called "seal imprints". The research object of "seal imprints" is broader and the research scope is larger. For example, "seal", vital in the identification of ancient calligraphy and painting, also serve as research object. Seals used by literati in Ming and Qing Dynasties, especially by calligraphers and painters, always share style, pattern, and layout. Such examples are not rare. For example, there are as many as a dozen or even 20 seals in Shen Zhou's paintings, such as "Qi Nan (启南)", "Shi Tian (石田)" ("Fig. 10") and "Bai Shi Weng (白石翁 )", confusing the scholars of painting and calligraphy. If one of the them is adopted as a yardstick of measurement, others with nuances may be excluded, which is unscientific. Once this is found, further screening is required.

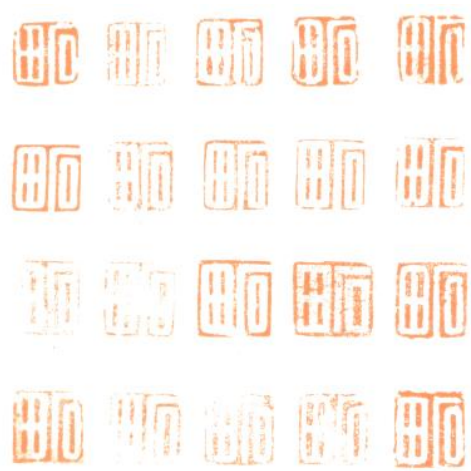

4 In the past, researchers generally accepted the view that "Zhi Yin Shu Kuan, Fang Yu Wen He (治印署款，昉于文 ( 彭) 何

( 震 ) : The emergence of the literati seal cutting is related to Wen Peng and He Zhen in Ming Dynasty.)". However, the seal of "Ding Chou Jin Shi (丁尹丑进士) " on the stone seal of Zhu Bao unearthed from the Ming Tomb in Shanghai has already found the side calligraphy of "Zhou Jing Zhuan". The analysis of the activity time of Zhu Bao shows that Zhou Jing was active in the years of Hongzhi, Zhengde and Jiajing, indicating the existence of people with independent consciousness and the behavior of seals cutting before Wen Peng. Zhu Qi. More information on Systematic Study on Seals of Literati in the Ming Dynasty and Its Artistic Features [J]. Journal of National Museum of Chinese History. Issue 9, 2018. 
Fig. 10. "Shi Tian (石田)".

The author holds that the phenomenon of "seals with same pattern" can be explained by following. The first is the aesthetic preference of painters and calligraphers, who simultaneously or successively engraved multiple seals in the same pattern. The second is the nuances caused by materials, liner, and even the abrasion of the original seal. The third is difference resulted from long time of use and the removal and modification of the silting mud on the surface. Other possibilities including copy of the lost one, and imitated one by later generations, should also be taken into account. The difference between Zhang Dageng Yin drawn by Cheng Ren and the unearthed one can be down to the first reason, that is, the sale owner engraved several seals of the same pattern successively. Such move reveal the recognition and preference of pattern and aesthetic style, but also consider credit and anti-counterfeiting function, which was adopted by many painters and calligraphers of the Qing Dynasty and the Republic of China.

In theory, seals for practical use in the Ming and Qing Dynasties should be circulated widely in the society, but the number of existing seals are less. The abrasion and damage of seals used by literati can be explained by its nature: personal use. The comparison between gold Zhang Dageng Yin and the imprints handed down for generations is an example of the subtle differences between the real object and the image literature, which proves that the number of private seals of the literati in Ming and Qing Dynasties is quite large, among which "seals with same pattern" are not rare. The mastery of this rule is of reference significance to the identification of seals handed down, ancient calligraphy and painting.

\section{References}

[1] Cultural Relics Management Institute of Fuyang. A Golden Seal of the Qing Dynasty was Discovered in Fuyang, Anhui [J]. Archaeology and Cultural Relics, Issue 5, 1999. Feng Qijun. The Golden Seal of Zhang Dageng Records the Rise and Fall of the Officials's Family (Photo courtesy of Yang Yubin). Fuyang Daily, March 26, 2015. (in Chinese)

[2] Collection of Cheng Xun Tang of Hong Kong. Wang Rencong's "Probe into the Golden Seal of "Chang Jun Xi", published in Collection of Thesis on "Gushan Zhengyin" of the Xiling Seal Engraver's Society International Seal Summit [C]. Xiling Seal Engraver's Society Publishing House, 2005 edition, Page 83. (in Chinese)

[3] Wang Rencong. Brief Discussion on the Golden Seal in Ancient China [C]. Collection of Thesis on "Gushan Zhengyin" of the 2ed Xiling Seal Engraver's Society International Seal Summit. Xiling Seal Engraver's Society Publishing House, 2008 edition, pp. 21-22. (in Chinese)

[4] Zhu Xiangxian. Yin Dian: Volume Six "Golden Seal", General Catelogue for the Complete Collection in Four Treasuries in Wen Yuan Ge of Qing Dynasty. (in Chinese)
[5] Yin Jishan. Volume 162 of (Qianlong) Jiangnan Tongzhi. General Catelogue for the Complete Collection in Four Treasuries in Wen Yuan Ge of Qing Dynasty. (in Chinese)

[6] Zhou Tianjue. Volume 9 and Volume 11 of (Daoguang) Fuyang County Annals. published in the 9th year of Daoguang in Qing Dynasty. (in Chinese)

[7] Dong Qichang. Ancient and Modern Seals. Selected Papers on Seal Studies edited by Han Tianheng, Xiling Seal Engraver's Society Publishing House, 2nd edition, 1999, p.441. 